ఠ

\title{
Lower neutrophil-to-lymphocyte ratio predicts high risk of multidrug-resistant Pseudomonas aeruginosa infection in patients with hospital-acquired pneumonia [Corrigendum]
}

Zhou YQ, Feng DY, Li WJ, et al. Ther Clin Risk Manag. 2018; 14:1863-1869.

On page 1863, the correct authorship and affiliations should read from:

Yu-Qi Zhou, ${ }^{1,2, *}$ Ding-Yun Feng, ${ }^{1,2, *}$ Wen-Juan Li, ${ }^{1,2}$ HaiLing Yang, ${ }^{1,2}$ Zhao-Ni Wang, ${ }^{3}$ Tian-Tuo Zhang, ${ }^{1,2}$ ZhuangGui Chen ${ }^{1,3}$

${ }^{1}$ Institute of Respiratory Diseases of Sun Yat-Sen University, Guangzhou, Guangdong, China; ${ }^{2}$ Department of Internal Medicine, Division of Respiratory Diseases, Guangzhou, Guangdong, China; ${ }^{3}$ Department of Pediatrics, The Third Affiliated Hospital of Sun Yat-sen University, Guangzhou, Guangdong, China
*These authors contributed equally to this work

to

Yu-Qi Zhou, ${ }^{1,2, *}$ Ding-Yun Feng, ${ }^{1,2, *}$ Wen-Juan Li, ${ }^{1,2}$ HaiLing Yang, ${ }^{1,2}$ Zhao-Ni Wang, ,,3 Tian-Tuo Zhang, ,,2 ZhuangGui Chen ${ }^{2,3}$

${ }^{1}$ Department of Internal Medicine, Division of Respiratory Diseases, The Third Affiliated Hospital, Sun Yat-sen University, Guangzhou, Guangdong, China; ${ }^{2}$ Institute of Respiratory Diseases, Sun Yat-sen University, Guangzhou, Guangdong, China; ${ }^{3}$ Department of Pediatrics, The Third Affiliated Hospital, Sun Yat-sen University, Guangzhou, Guangdong, China

*These authors contributed equally to this work
Therapeutics and Clinical Risk Management

\section{Publish your work in this journal}

Therapeutics and Clinical Risk Management is an international, peerreviewed journal of clinical therapeutics and risk management, focusing on concise rapid reporting of clinical studies in all therapeutic areas, outcomes, safety, and programs for the effective, safe, and sustainec use of medicines. This journal is indexed on PubMed Central, CAS,

\section{Dovepress}

EMBase, Scopus and the Elsevier Bibliographic databases. The manuscript management system is completely online and includes a very quick and fair peer-review system, which is all easy to use. Visit http://www.dovepress.com/testimonials.php to read real quotes from published authors. 